\title{
Serum hepatic biochemical activity in two populations of workers exposed to styrene
}

\author{
C A Brodkin, J-D Moon, J Camp, D Echeverria, C A Redlich, R A Willson, H Checkoway
}

Department of Medicine, University of Washington, Seattle,

WA, USA

C A Brodkin

R A Willson

Department of Environmental Health, Harborview Medical Center, Box 359739, 325 9th Avenue, Seattle, WA 98104, USA

C A Brodkin

J-D Moon

J Camp

H Checkoway

Chonnam National

University,

Department of

Preventive Medicine;

Kwangju, Korea

J-D Moon

Battelle Seattle

Research Center;

Seattle, WA, USA

D Echeverria

Yale University, Department of Internal Medicine;

New Haven, CT, USA

C A Redlich

Harborview Medical Center, Chief of

Hepatology; Seattle,

WA, USA

R A Willson

Correspondence to:

Dr C A Brodkin

sarabell@u.washington.edu

Accepted 27 September 2000

\begin{abstract}
Objective-To determine whether hepatic biochemical changes, as measured by routinely available tests indicative of hepatocellular necrosis, cholestasis, or altered hepatic clearance of bilirubin, occur in association with low to moderate exposure to styrene commonly experienced in industrial production.

Methods-Two independent cross sectional studies were performed comparing serum hepatic transaminases (alanine aminotransferase (ALT) and aspartate aminotransferase (AST)), cholestatic enzymes (alkaline phosphatase (AP) and $\gamma$ glutamyl transpeptidase (GGT)), and bilirubin in (a) 47 workers of fibreglass reinforced plastics who were exposed to styrene and (b) 21 boat and tank fabricators, with separate referent groups of unexposed workers. Exposure to styrene was assessed in air by dosimetry, and in venous blood by headspace analysis. $\mathrm{He}-$ patic biochemical variables were assessed across strata of exposure to styrene defined as $25 \mathrm{ppm}$ in air, or $0.275 \mathrm{mg} / 1$ in blood, adjusting for age, sex, body mass index, and ethanol consumption.
\end{abstract}

Results-A consistent and significant linear trend for increasing direct bilirubin and direct/total bilirubin ratio was found in association with increasing exposure to styrene, by both air and blood monitoring, in both studies. Mean direct bilirubin concentrations increased from 0.05-0.08 $\mathrm{mg} \%$ in referents to $0.12-0.19$ in workers exposed above $25 \mathrm{ppm}$, with a significant exposure-response trend $(p<0.005)$. Significantly increased direct/total bilirubin ratios, ranging from 0.22 to 0.35 were associated with exposure to styrene $(\mathbf{p}<0.001)$, indicating diminished hepatic clearance of conjugated bilirubin. Also, a significant linear association between the hepatic transaminases ALT and AST and exposure to styrene was found in pooled regression analyses, with an increase in AP of about $10 \mathrm{IU} / \mathrm{ml}$ in workers exposed above $25 \mathrm{ppm}$ air or $0.275 \mathrm{mg} / 1$ blood styrene in pooled analyses from both studies.

Conclusions-The consistent finding of increased direct bilirubin and AP concentrations in these two independent studies provides evidence for diminished hepatic clearance of conjugated bilirubin with associated cholestasis in workers exposed to styrene. The finding of a significant linear association between hepatic transami- nase concentrations and exposure to styrene in pooled analyses is consistent with mild hepatic injury and associated metabolic dysfunction.

(Occup Environ Med 2001;58:95-102)

Keywords: hepatotoxicity; styrene; surveillance; bilirubin; aminotransferases

Concern for potential hepatotoxicity associated with exposure to styrene has been based primarily on the critical role of the liver in styrene metabolism. Biotransformation of styrene occurs by microsomal mixed function oxygenases to the reactive intermediate styrene-7,8oxide, ${ }^{1}$ that can bind covalently with hepatic macromolecules and lipid membranes to cause hepatocellular injury. ${ }^{2-4}$ Evidence for hepatocellular necrosis induced by styrene has been shown experimentally at high exposures (375$400 \mathrm{mg} / \mathrm{kg}$ ), with histological focal necrosis correlating well with increases in hepatic transaminases (alanine (ALT) and aspartate $(\mathrm{AST}))^{56}$ in rats fed styrene. Although severe hepatic necrosis is found in mice at concentrations as low as $250 \mathrm{ppm}$ air, ${ }^{7}$ lesser effects occur in rats at similar or higher doses. ${ }^{689}$

Studies considering hepatotoxicity associated with exposure to styrene in humans have yielded variable results, and have not systematically considered potential confounders including ethanol consumption, body mass index, and viral infection. Several epidemiological studies of workers exposed to relatively high concentrations of styrene, ranging from 50 to $300 \mathrm{ppm}$, have found increases in serum hepatic transaminase ${ }^{10}$ and $\gamma$-glutamyl transferase (GGT) concentrations ${ }^{11-13}$ suggesting hepatic necrosis and cholestasis, respectively.

Few studies have considered hepatic effects of styrene at concentrations within the $\mathrm{Na}$ tional Institute for Occupational Safety and Health (NIOSH) permissible exposure limit (PEL) of $50 \mathrm{ppm}$, which are commonly experienced in current industrial production. ${ }^{14}$ The question as to whether exposure to styrene at this concentration is associated with hepatotoxicity is of strong public health interest, with over 200000 workers worldwide exposed on a daily basis. ${ }^{3}$ Further, hepatic injury manifest by cholestatic or more subtle changes in metabolic clearance may not be detectable by hepatic transaminases (AST and ALT), which are used routinely for screening exposed workers.

To consider the question of whether hepatic effects occur at styrene concentrations near or below $50 \mathrm{ppm}$, and whether these effects are detectable by routinely available tests of hepatic biochemical function, we conducted 
two independent cross sectional studies of workers exposed to styrene, assessing (a) hepatic transaminase concentrations which reflect active hepatic necrosis, (b) hepatic enzymes associated with cholestasis, and $(c)$ direct bilirubin concentrations which reflect hepatic clearance of endogenous organic anions.

\section{Methods}

SUBJECT SELECTION

Cross sectional studies of biochemical hepatic function were performed in two independent populations of workers exposed to styrene:

Study 1

A health study of the workers was conducted at three fibreglass reinforced plastic plants in western Washington state. Sixty fabrication workers, representing the total workforce regularly exposed to styrene, were recruited as the exposed group. Among this group, 47 workers $(78 \%)$ with air and blood styrene concentration measurements, as well as blood collection for hepatic biochemical data, were included. Eighteen machine assembly workers not exposed to styrene were recruited as referent subjects. Non-exposure to styrene was established by full shift passive dosimetry. Among this group, $14(78 \%)$ with hepatic biochemical data were included for the current study. All referent workers were employed at one of the plants, in a separate building where styrene and other organic solvents were not used.

Study 2

The second health study of workers was conducted at 13 boat and tank fabrication factories. Twenty four production workers, representing the total workforce regularly using styrene, were recruited as the exposed group. Twenty nine laundry workers, recruited from a factory where no organic solvents-including styrene-were used, represented the referent group. Non-exposure was established by full shift passive dosimetry. Subjects had personal blood and air styrene concentration measurements, as well as blood collection for hepatic biochemical data.

Serological tests for active viral hepatitis, including hepatitis B core antibody, hepatitis B surface antigen, and hepatitis $\mathrm{C}$ antibody (ELISA II method) were available for study 2 only, and were used to exclude subjects with evidence of active hepatitis. Three out of 29 subjects $(10.3 \%)$ from the referent group, and $3 / 24(12.5 \%)$ from the exposed group, respectively, had serological abnormalities suggestive of active viral hepatitis, resulting in 26 referent and 21 exposed workers in study 2 eligible for participation.

Demographic information, as well as height, weight, employment history, smoking, alcohol use, and medical history was obtained through a self administered questionnaire completed during the workshift. Both studies were approved by the University of Washington Human Subjects Review Committee; informed consent, explaining the purpose and proce- dures of the study, was obtained for all participating workers.

EXPOSURE ASSESSMENT

All blood and air exposure sampling was performed midweek (Wednesday or Thursday). To assess the effect of recent exposure to styrene on hepatic function, all exposure sampling was conducted on the same day that blood specimens were obtained for hepatic biochemical measurements. Full shift exposure monitoring of styrene was performed with personal breathing zone passive dosimeters (SKC Anasorb, model No 530-11). Eight hour time weighted average exposures were measured by gas chromatography. ${ }^{15}$ Blood styrene concentrations, available for 66 of 68 exposed workers, were measured by headspace gas chromatography with automatic cryogenic focusing and high resolution capillary chromatography. ${ }^{16}$ Fifty three $(80 \%)$ exposed workers had blood styrene concentrations less than half the American Conference of Governmental Industrial Hygienists (ACGIH) biological exposure index (BEI $0.275 \mathrm{mg} / \mathrm{l}$ ), whereas 13 $(20 \%)$ had greater values.

Study subjects in each population were classified into one of three exposure groups based on both air and blood styrene concentrations, respectively. Strata for exposed workers were defined as either one half the NIOSH PEL of $25 \mathrm{ppm}$ or the ACGIH threshold limit value (TLV) of $20 \mathrm{ppm}$, respectively, for styrene in air; and one half the BEI for styrene in blood $(0.275 \mathrm{mg} / \mathrm{l})$.

Use of fibreglass reinforced material among workers exposed to styrene in both studies also involves intermittent exposure to dust, nonvolatile waxes, acetone, and silicone based releasing agents; concentrations of these agents were not measured.

\section{BIOCHEMICAL MEASUREMENTS}

Biochemical measurements were selected to assess hepatic injury associated with either necrosis, cholestasis, or altered hepatic clearance. Tests of liver injury associated with necrosis included the serum hepatic transaminases ALT and AST. Hepatic injury with associated necrosis is accompanied by release of these transaminases into plasma, allowing measurement of enzyme activity in serum by standard clinical laboratory methods. ${ }^{17}$ Tests of hepatic cholestasis included alkaline phosphatase (AP) and $\gamma$-glutamyl transferase (GGT), also measured by standard clinical laboratory methods. Hepatic cholestasis is associated with induction of canalicular $\mathrm{AP}^{1718}$ and correlates well with increases in biliary $\gamma$-glutamyl transpeptidase. ${ }^{19}$

Hepatic clearance was assessed by measurements of total and direct bilirubin concentrations. Bilirubin, a degradation product of haeme (chiefly through red blood cell senescence), is conjugated in the liver, and transported actively into bile canaliculi; a small amount of this esterified bilirubin, about $4 \%$ in humans, refluxes into plasma. The conjugated form can be measured directly by standard diazo reaction methods, ${ }^{20}$ and is termed direct 
bilirubin. In this method, bilirubin is cleaved in acidic aqueous medium (containing sulfanilic acid and sodium nitrite) with a diazo reagent (Amresco, Solon, Ohio) to form a dipyrrolic azo derivative, and measured spectrophotometrically at $A_{570 \mathrm{~nm}}$. Conjugated bilirubins are usually efficiently secreted into the bile by active transport, ${ }^{21}$ however their clearance can be diminished with hepatic parenchymal and cholestatic injury, increasing the percentage of direct (conjugated) bilirubin in plasma. Direct reacting bilirubin values exceeding $0.3 \mathrm{mg} / \mathrm{dl}$, or $20 \%-30 \%$ of total plasma bilirubins are indicative of conjugated hyperbilirubinaemia. ${ }^{22} 23$

All hepatic biochemical tests were performed at a hospital based clinical laboratory (Laboratory of Pathology; Seattle, WA). The 95th percentile values for these hepatic biochemical variables in the laboratory reference population were as follows: ALT $>50 \mathrm{IU} / \mathrm{ml}$; AST $>41$ $\mathrm{IU} / \mathrm{ml}$; GGT > $65 \mathrm{IU} / \mathrm{ml}$; AP > $115 \mathrm{IU} / \mathrm{ml}$; total bilirubin $1.2 \mathrm{mg} / \mathrm{dl}$; and direct bilirubin 0.3 $\mathrm{mg} / \mathrm{dl}$.

DATA ANALYSIS

The primary methods for analysis of hepatic biochemical tests involved a comparison of means among referent, low exposure, and moderate to high exposure groups, as defined by air and blood styrene concentrations, by analysis of variance (ANOVA) and test of linear trend. Because referent and exposed groups differed in varying degrees for age and sex (table 1), mean values were adjusted for these potentially confounding variables, by analysis of covariance (ANCOVA). Although alcohol consumption was quite low and body mass index was similar in the comparison groups, these important potential confounders - which have not been systematically controlled in previous studies-were also included in the covariance model. Comparisons of median values among the exposure categories were also performed for all hepatic biochemical variables, with the Kruskal-Wallis test, to find whether potential undue influences of extreme values on comparisons of means occurred between groups. Pooled analyses, combining referent workers and exposed workers from both studies were performed to assess consistency of trends in the individual studies and enhance statistical power. Multiple linear regression was used to model specific hepatic biochemical test measurements (dependent variables) as a function of both air and blood exposure to styrene concentrations, as well as the potential confounders age, sex, body mass index, and alcohol consumption (independent variables).

\section{Results}

SUBJECT CHARACTERISTICS

Demographic and employment data, as well as the potentially confounding variables of age, race, sex, body mass index, and alcohol consumption, are presented in table 1 for exposed and referent subjects in study populations 1 and 2 .

\section{Study population 1}

The distributions of age, ethnicity, body mass index, and alcohol consumption were similar in the exposed and referent groups. Alcohol intake was quite low overall, with $45 \mathrm{~g}$ alcohol (about 3 drinks a week) consumed on average. Duration of employment was greater in the referent group, with a greater percentage of women in the exposed group.

\section{Study population 2}

The chief demographic difference between referent and exposed groups in this study was the representation of women $(54 \% v 5 \%$, respectively, $\mathrm{p}<0.01)$. The referent group was also significantly older (37 $v 32$ years old), with greater ethnic diversity. Although alcohol intake was slightly greater, but not significantly so, in the exposed group, reported alcohol use was low overall, with less than $60 \mathrm{~g}$ or 4 drinks a week consumed in either group. Body mass index and duration of employment were similar between the groups.

Air styrene concentrations were similar in studies 1 and 2, with means in the $20-25 \mathrm{ppm}$ range. The range of air styrene concentrations in study 1 was $0.78-85.3 \mathrm{ppm}$, with a maximum air styrene concentration in study 2 of $110 \mathrm{ppm}$. Although air concentrations were lower in study 1 , blood styrene concentrations were higher $(0.20 v 0.13 \mathrm{mg} / \mathrm{l})$, suggesting the possibility of increased dermal routes of exposure among boat and tank fabricators.

BIOCHEMICAL MARKERS OF HEPATOCELLULAR NECROSIS

Median, mean, and adjusted mean values for ALT and AST by air styrene concentrations are presented in table 2 for studies 1 and 2. In study 1, no significant trend for increasing hepatic transaminase activity was found for either ALT or AST, across the referent, low,

Table 1 Demographic data, lifestyle, and exposure characteristics

\begin{tabular}{|c|c|c|c|c|}
\hline & \multicolumn{2}{|l|}{ Study 1} & \multicolumn{2}{|l|}{ Study 2} \\
\hline & Referent & Exposed & Referent & Exposed \\
\hline Subjects (n) & 14 & 47 & 26 & 21 \\
\hline Age $(\mathrm{y}$, mean $(\mathrm{SD}))$ & $31.6(2.4)$ & $31.2(1.1)$ & $37.3^{\star}(1.8)$ & $32.1(1.9)$ \\
\hline Sex $(\%$ men $)$ & 86 & 67 & $46^{\star \star \star}$ & 95 \\
\hline Ethnicity (\% white) & 100 & 86 & $69^{\star \star}$ & 100 \\
\hline $\mathrm{BMI}\left(\mathrm{wt} / \mathrm{ht}^{2}\right.$, mean $\left.(\mathrm{SEM})\right)$ & $25.8(0.8)$ & $25.4(0.8)$ & $24.6(0.8)$ & $24.7(0.8)$ \\
\hline Drinking (g/week, mean (SEM)) & $36 \quad(13.5)$ & $45 \quad(7.5)$ & $36.0(6.0)$ & $60.0(6.0)$ \\
\hline Duration of employment (y mean (SEM)) & $6.5(2.1)$ & $3.8(0.7)$ & $4.2(1.0)$ & $5.5(1.4)$ \\
\hline Air styrene concentration (ppm mean (SEM)) & - & $21.8(3.5)$ & - & $24.1(5.4)$ \\
\hline Blood styrene concentration (mg/l mean (SEM)) & - & $0.20(0.05)$ & - & $0.13(0.04)$ \\
\hline
\end{tabular}

${ }^{\star} \mathrm{p}<0.05 ;{ }^{\star \star} \mathrm{p}<0.01 ;{ }^{\star \star \star} \mathrm{p}<0.001$. 
Table 2 Hepatic transaminase activity (IU/ml) by air styrene concentration (ppm)

\begin{tabular}{|c|c|c|c|c|c|c|c|c|}
\hline & \multicolumn{4}{|l|}{ Study 1} & \multicolumn{4}{|l|}{ Study 2} \\
\hline & $\begin{array}{l}\text { Referent } \\
(n=14)\end{array}$ & $\begin{array}{l}<25 \\
(n=30)\end{array}$ & $\begin{array}{l}>25 \\
(n=17)\end{array}$ & $p$ Value & $\begin{array}{l}\text { Referent } \\
(n=26)\end{array}$ & $\begin{array}{l}<25 \\
(n=11)\end{array}$ & $\begin{array}{l}>25 \\
(n=10)\end{array}$ & $p$ Value \\
\hline \multicolumn{9}{|l|}{ ALT: } \\
\hline Median & 25.0 & 21.0 & 24.0 & 0.78 & 16.5 & 22.0 & 20.5 & 0.22 \\
\hline Mean (SE) & $24.9(3.3)$ & $23.5(2.2)$ & $28.1(3.9)$ & 0.53 & $20.4(2.4)$ & $31.4(7.7)$ & $24.6(3.9)$ & 0.34 \\
\hline $\begin{array}{l}\text { Adjusted } \\
\text { meant }\end{array}$ & $23.6(3.0)$ & $22.3(2.1)$ & $30.2(2.9)$ & 0.10 & $19.6(3.6)$ & $31.1(5.1)$ & $26.9(5.6)$ & 0.25 \\
\hline \multicolumn{9}{|l|}{ AST: } \\
\hline Median & 20.5 & 19.0 & 23.0 & 0.46 & 19.0 & 31.0 & $29.5^{\star \star}$ & $<0.001$ \\
\hline Mean (SE) & $22.9(3.4)$ & $19.6(1.1)$ & $22.5(1.7)$ & 0.36 & $19.5(1.5)$ & $31.5(2.3)$ & $31.4(2.2)^{\star}$ & $<0.001$ \\
\hline $\begin{array}{l}\text { Adjusted } \\
\text { meant }\end{array}$ & $22.9(2.1)$ & $20.0(1.5)$ & $22.0(2.0)$ & 0.49 & $20.4(1.6)$ & $30.4(2.4)$ & $30.3(2.6)$ & 0.004 \\
\hline
\end{tabular}

${ }^{\star} \mathrm{p}<0.05 ;{ }^{\star \star} \mathrm{p}<0.01$.

†ANCOVA adjusted mean for age, sex, body mass index, and alcohol consumption (g/week).

$\mathrm{ALT}=$ alanine aminotransferase; $\mathrm{AST}=$ aspartate aminotransferase.

Table 3 Hepatic biomarkers (IU/ml) of cholestasis by air styrene concentration (ppm)

\begin{tabular}{|c|c|c|c|c|c|c|c|c|}
\hline & \multicolumn{4}{|l|}{ Study 1} & \multicolumn{4}{|l|}{ Study 2} \\
\hline & $\begin{array}{l}\text { Referent } \\
(n=14)\end{array}$ & $\begin{array}{l}<25 \\
(n=30)\end{array}$ & $\begin{array}{l}>25 \\
(n=17)\end{array}$ & p Value & $\begin{array}{l}\text { Referent } \\
(n=26)\end{array}$ & $\begin{array}{l}<25 \\
(n=11)\end{array}$ & $\begin{array}{l}>25 \\
(n=10)\end{array}$ & $p$ Value \\
\hline \multicolumn{9}{|l|}{$\mathrm{AP}:$} \\
\hline Median & 52.0 & 51.5 & 58.0 & 0.18 & 57.0 & 59.0 & 66.0 & 0.12 \\
\hline Mean (SE) & $54.9(3.6)$ & $56.6(2.8)$ & $61.7(3.3)$ & 0.38 & $57.8(2.9)$ & $67.2(6.1)$ & $68.7(4.2)$ & 0.11 \\
\hline $\begin{array}{l}\text { Adjusted } \\
\text { mean }\end{array}$ & $53.6(3.9)$ & $55.3(2.8)$ & $63.2(3.7)$ & 0.16 & $60.1(3.7)$ & $65.1(5.4)$ & $65.0(5.9)$ & 0.74 \\
\hline \multicolumn{9}{|l|}{ GGT: } \\
\hline Median & 14.5 & 17.5 & 17.0 & 0.89 & 16.5 & 21.0 & 19.5 & 0.19 \\
\hline Mean (SE) & $26.2(6.8)$ & $19.9(2.5)$ & $19.3(2.9)$ & 0.44 & $19.8(2.6)$ & $35.6(11)$ & $24.1(3.8)$ & 0.30 \\
\hline $\begin{array}{l}\text { Adjusted } \\
\text { mean }^{\star}\end{array}$ & $24.2(4.2)$ & $18.8(3.0)$ & $21.1(4.1)$ & 0.59 & $20.1(3.9)$ & $33.6(5.7)$ & $25.4(6.2)$ & 0.20 \\
\hline
\end{tabular}

^ANCOVA adjusted for age, sex, body mass index, and alcohol consumption (g/week).

$\mathrm{AP}=$ alkaline phosphatase; $\mathrm{GGT}=\gamma$-glutamyl transferase.

and moderate to high air styrene concentrations. Although an increase in mean ALT $(30.2$ $\mathrm{IU} / \mathrm{ml}$ ) was found in the highest exposure group, this was not accompanied by a concomitant increase in median concentration of ALT. By contrast, higher mean and median ALT and AST concentrations were found in study 2 for the exposed than the referent groups, with a significant increase for AST concentrations $(\mathrm{p}<0.001)$, although the trend did not increase monotonically. The differences in hepatic transaminase concentrations in study 2 were greater in the low $(<25 \mathrm{ppm})$ than the high exposure group ( $\geqslant 25 \mathrm{ppm}$ ), providing no evidence of an exposure-response pattern among exposed workers. Crude and adjusted mean concentrations for all of the hepatic transaminases in this study were similar, indicating no evidence of confounding by demographic factors or alcohol intake.

BIOCHEMICAL MARKERS OF HEPATIC CHOLESTASIS Median, mean, and adjusted mean values for hepatic cholestatic enzymes by air styrene concentration are presented in table 3 . In study 1 , adjusted mean concentrations of AP increased across the exposure strata, ranging from 54 to $63 \mathrm{IU} / \mathrm{ml}$, in a non-significant trend $(\mathrm{p}=0.16)$. An increase in median AP concentration occurred only among the highest exposure group $(\mathrm{p}=0.18)$. In study 2 , a linear increase in both median and mean AP values was found across exposure categories; as in study 1 , this did not reach significance.

In contrast with $\mathrm{AP}, \mathrm{GGT}$ concentrations showed no consistent trends with exposure in either study.
BIOCHEMICAL MARKERS OF ALTERED HEPATIC CLEARANCE

Mean total and direct bilirubin concentrations, as well as direct/total bilirubin ratios for studies 1 and 2, are displayed graphically by air styrene concentrations in figures 1 and 2, respectively. These values were similar in magnitude and significance to adjusted mean and median values (not displayed). A similar pattern of bilirubin concentrations was found in both studies. Although total bilirubin concentrations did not vary significantly between exposure categories, both direct bilirubin concentrations and direct/total bilirubin ratio were increased in workers exposed to styrene, with a significant linear trend with increasing exposure. In study 1 , mean (SE) direct bilirubin concentrations were $0.05(0.02)$ in the control group, increasing to $0.11(0.01)$ in workers

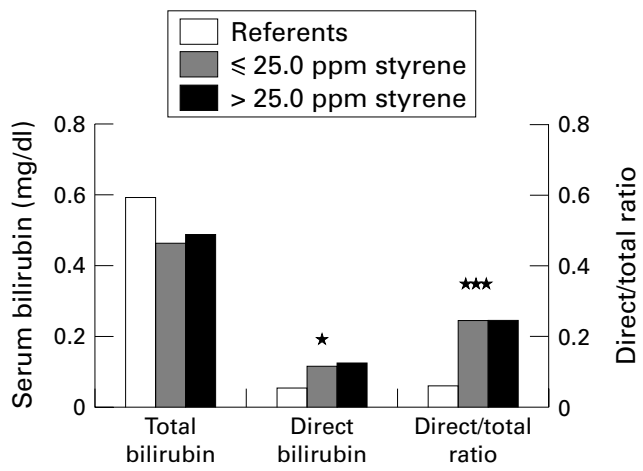

Figure 1 Mean total bilirubin, direct bilirubin, and direct/total bilirubin ratio, by air styrene concentration (ppm) in study 1. ${ }^{\star} p<0.05$ (ANOVA); ${ }^{\star \star *} p<0.001$, test for linear trend. 


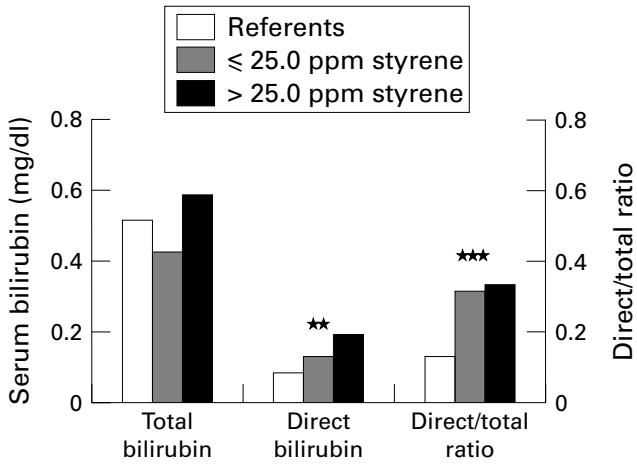

Figure 2 Mean total bilirubin, direct bilirubin, and direct/total bilirubin ratio, by air styrene concentration (ppm) in study 2. ${ }^{\star \star} p<0.01$ ( ANOVA); ${ }^{\star \star \star} p<0.001$, test for linear trend.

with $<25 \mathrm{ppm}$ exposure to styrene, and 0.12 (0.02) $\mathrm{mg} / \mathrm{ml}$ in workers with $\geqslant 25 \mathrm{ppm}$ exposure. Similarly, in study 2 , direct bilirubin concentrations ranged from $0.08(0.02) \mathrm{mg} / \mathrm{ml}$ in the control group, $0.13(0.03)$ in the low exposure group, and $0.19(0.03)$ in the moderate to high exposure group. The proportion of direct to total bilirubin in exposed workers was consistently increased, with a ratio in the 0.22 0.35 range, approaching the 0.30 ratio defined as clinically notable in direct hyperbilirubinaemia. By contrast, direct to total bilirubin ratios for referent workers were normal, in the range of $9 \%-16 \%$ for both studies 1 .

Table 4 Adjusted differences in hepatic biochemical function measurementst by air and blood concentration of styrene (pooled data from study 1 and study 2)

\begin{tabular}{|c|c|c|c|c|}
\hline \multirow[b]{2}{*}{ Hepatic biochemical marker } & \multicolumn{2}{|c|}{ Air styrene (ppm) } & \multicolumn{2}{|c|}{ Blood styrene $(\mathrm{mg} / \mathrm{l})$} \\
\hline & $<25$ & $>25$ & $<0.275$ & $>0.275$ \\
\hline AST (IU/ml) & $2.3 \ddagger$ & 4.9 & 3.5 & 2.4 \\
\hline ALT (IU/ml) & 4.1 & $8.1^{\star}$ & 5.6 & 5.6 \\
\hline GGT (IU/ml) & 3.9 & 4.9 & 4.6 & 2.5 \\
\hline $\mathrm{AP}(\mathrm{IU} / \mathrm{ml})$ & 4.2 & $10.3^{\star}$ & 5.6 & $10.7^{\star}$ \\
\hline Direct bilirubin (mg/dl) & $0.05^{\star \star}$ & $0.08^{\star \star}$ & $0.06^{\star \star}$ & $0.08^{\star \star}$ \\
\hline Direct/total bilirubin ratio & $0.19^{\star \star \star}$ & $0.19^{\star \star \star}$ & $0.19^{\star \star \star}$ & $0.18^{\star \star \star}$ \\
\hline
\end{tabular}

${ }^{\star} \mathrm{p}<0.05 ;{ }^{\star \star} \mathrm{p}<0.01 ;{ }^{\star \star \star}{ }^{\star} \mathrm{p}<0.001$.

†From multiple linear regression models regressing hepatic biochemical function measurement on air and blood concentrations of styrene, respectively, with covariates: age, sex, body mass index, and alcohol consumption ( $\mathrm{g} /$ week).

$\ddagger$ Difference in hepatic biochemical marker measurement in exposed group compared with unexposed referent group. All differences are in positive direction, representing values greater than the referent group.

$\mathrm{ALT}=$ alanine aminotransferase; $\mathrm{AST}=$ aspartate aminotransferase; $\mathrm{AP}=$ alkaline phosphatase; GGT $=\gamma$-glutamyl transferase.

Table 5 Association between hepatic biochemical function measurements $f$ and continuous air concentrations of styrene for pooled data from study 1 and study 2

\begin{tabular}{lllllll}
\hline \multicolumn{7}{c}{ Partial regression coefficients } \\
\cline { 2 - 7 } Hepatic biochemical marker $\neq$ & Air styrene & Age & Sex & BMI & Alcohol & $R^{2}$ \\
\hline AST (IU/ml) & $0.22^{\star \star \star}$ & $0.46^{\star}$ & $10.27^{\star \star}$ & -0.19 & 0.23 & 0.27 \\
ALT (IU/ml) & $0.52^{\star \star \star}$ & $1.32^{\star}$ & $15.15^{\star \star}$ & 0.34 & 0.39 & 0.27 \\
GGT (IU/ml) & 0.05 & $1.26^{\star \star \star}$ & $14.75^{\star \star}$ & -0.02 & 1.08 & 0.34 \\
AP (IU/ml) & 0.12 & 0.30 & 9.44 & -0.08 & 0.35 & 0.12 \\
Direct bilirubin (mg/dl) & $0.0007^{\star}$ & -0.0005 & 0.03 & -0.003 & 0.003 & 0.18 \\
Direct/total bilirubin ratio & 0.0005 & 0.001 & $0.09^{\star \star}$ & $-0.007^{\star}$ & $0.007^{\star}$ & 0.26
\end{tabular}

${ }^{\star} \mathrm{p}<0.05 ;{ }^{\star \star} \mathrm{p}<0.01 ;{ }^{\star \star \star} \mathrm{p}<0.001$.

$\dagger$ From multiple linear regression models regressing hepatic biochemical function measurement on continuous air concentrations of styrene (ppm), age (y), sex (male), body mass index, and alcohol consumption (g/week).

$\mathrm{ALT}=$ alanine aminotransferase; $\mathrm{AST}=$ aspartate aminotransferase; $\mathrm{AP}=$ alkaline phosphatase; GGT $=\gamma$-glutamyl transferase.
BIOCHEMICAL MARKERS IN POOLED ANALYSES FROM STUDY 1 AND STUDY 2

To further assess trends in hepatic biochemical markers associated with exposure to styrene, data from studies 1 and 2 were pooled. Differences in specific biochemical measurements in exposed groups, compared with non-exposed referents, are presented in table 4 . As well as the significant increases in direct bilirubin found across strata of exposure to styrene in both air and blood, similar to the individual studies, a significant increase was also found for $\mathrm{AP}$ in the pooled analyses. After adjusting for the effects of age, body mass index, sex, and alcohol consumption, styrene concentrations greater than $25 \mathrm{ppm}$ in air or $0.275 \mathrm{mg} /$ in blood were associated with a $10 \mathrm{IU} / \mathrm{ml}$ increase in $\mathrm{AP}$, with an increase in ALT of $8 \mathrm{IU} / \mathrm{ml}$ in association with air styrene concentrations only. In regression analyses stratifying exposure to styrene at the current ACGIH TLV of 20 ppm, rather than $25 \mathrm{ppm}$, no material difference in either magnitude or trend of the coefficients for any hepatic biochemical variable was found.

The quantitative association between hepatic biochemical markers and air exposure to styrene as a continuous variable is presented in table 5. Significant linear associations were found for the hepatic transaminases AST and ALT, with a 2-5 IU $/ \mathrm{ml}$ increase, and direct bilirubin with a $0.007 \mathrm{mg} \%$ increase associated with a $10 \mathrm{ppm}$ increase in exposure to styrene. A modest $1.2 \mathrm{IU} / \mathrm{ml}$ increase was found for $\mathrm{AP}$, which did not reach significance. Significant linear increases in transaminase and GGT concentrations were also found for increasing age and male sex in the model, but not for body mass index or alcohol consumption.

\section{Discussion}

In these two independent cross sectional studies of workers exposed to styrene, we assessed routinely available tests of hepatic biochemical function associated with either hepatic necrosis, cholestasis, or altered hepatic clearance, relative to exposure to styrene near or below the NIOSH PEL of $50 \mathrm{ppm}$. The ability to use separate studies from diverse occupational settings, as well as control for potential confounders including age, sex, alcohol use, chronic hepatitis B and C infection (study 2), and obesity - which have not been systematically considered in previous studies-allows an opportunity to assess the consistency of biochemical changes at styrene concentrations commonly experienced in workplaces today.

A consistent and significant association between biochemical changes and concentration of styrene was found only for biomarkers of altered hepatic clearance in the two studies. A significant linear trend for direct bilirubin concentrations was found for both air and blood styrene concentrations in studies 1 and 2, with significant exposure-response patterns across increasing exposure strata. Although mean direct bilirubin concentrations were within clinically defined normal limits for all exposure groups, the proportion of direct to total bilirubin levels (direct/total bilirubin 
ratio) was significantly increased in exposed workers in both studies, ranging from $22 \%$ to $35 \%$, indicating a mild subclinical trend towards direct hyperbilirubinaemia.

Notably, a significant linear association was found for the hepatic transaminases ALT and AST, as well as direct bilirubin, with increasing air styrene concentrations (table 5). Such an association was found for AP only in association with air and blood styrene concentrations above $25 \mathrm{ppm}$ (table 4). This finding is consistent with mild hepatic parenchymal injury, with associated cholestatic effects at higher styrene concentrations. This may account for the diminished clearance of direct bilirubin found in this investigation, that can be markedly impaired in the setting of cholestasis. $^{24}$ Although no concurrent exposureresponse association was found for GGT in this investigation, increases of this cholestatic enzyme have been found in other populations exposed to styrene, generally at higher styrene concentrations. ${ }^{1112} 25$

Placed in the context with previous studies that show hepatic transaminase increases in workers exposed to higher styrene concentrations of $100-300 \mathrm{ppm},{ }^{10}$ our findings suggest a milder hepatic effect at concentrations within permissible standards, with modest increases in hepatic biochemical variables. ${ }^{26}$ The possibility that lifestyle or demographic differences between the referent and exposed groups in study 2 accounted for the dichotomous changes in transaminase concentrations cannot be excluded. Although alcohol intake was greater among exposed workers, overall alcohol intake was extremely low in both exposed and referent groups; furthermore, neither AST nor GGT concentrations - both sensitive to alcohol consumption-were effected by adjustment for alcohol consumption in the analysis. In regression analyses, no significant association was found for alcohol consumption (table 5). Also, mean AST/ALT ratios in both studies were uniformly low, ranging from 0.83 to 1.27 for all exposure groups, a ratio more consistent with solvent induced effects than the twofold ratio indicative of alcoholic liver disease. ${ }^{27} 28$ Similarly, whereas age and sex effects can affect biochemical variables of hepatic function, ${ }^{17}$ adjustment for these potential confounders altered neither the magnitude nor significance of the mean transaminase changes.

Our finding of an association between the direct bilirubin fraction and AP relative to exposure to styrene suggests that milder hepatocellular dysfunction, characterised by diminished clearance of endogenous organic acids such as conjugated bilirubin, in conjunction with mild cholestasis, may be occurring in association with mild inflammatory changes. Direct bilirubin, as measured by the standard diazo reaction (van den Bergh) methods used in this study, provides an estimate of conjugated bilirubin. ${ }^{22}$ Because hepatic clearance of bilirubin requires conjugation to a carboxylic ester (chiefly glucuronic acid) and energy dependent, active hepatocanalicular transport, its excretion is highly susceptible to hepatocellular injury and cholestasis. ${ }^{20} 29$
Among four previous studies that assessed bilirubin concentrations in workers exposed to styrene, three indicated evidence of hyperbilirubinaemia consistent with our findings. Katz reported a $35.4 \%$ prevalence of increased bilirubin concentrations among 526 workers in processing of divinyl styrene synthetic rubber who were exposed to styrene at about 20 ppm. ${ }^{30}$ Similarly, Oltramare et al reported increased bilirubin concentrations in three out of five styrene resin workers with variable exposure, ranging from 20 to $560 \mathrm{ppm} .{ }^{31}$ Vihko et al reported a $10 \%$ prevalence of clinically increased serum bilirubin concentrations among 25 workers exposed to $420 \mathrm{mg} / \mathrm{m}^{3}$ styrene, and found only a $4 \%$ prevalence of increases in direct bilirubin concentrations. ${ }^{32}$ By contrast, Theiss et al reported only a $2.4 \%$ prevalence of total bilirubin concentrations beyond the reference range in styrene production workers. ${ }^{11}$ They, however, did not assess the direct bilirubin fraction.

Our finding of increased direct bilirubin is consistent with several studies that have found increased concentrations of serum bile acids in populations exposed to styrene, in the absence of other substantial liver function abnormalities. ${ }^{32}$ By contrast with the $10 \%$ prevalence in serum bilirubin elevations in the population exposed to styrene already mentioned, Vihko et al found a $20 \%$ prevalence $(\mathrm{p}<0.001)$ of increase in chenodeoxycholic acid, indicating that serum bile acids may provide greater sensitivity for styrene induced hepatic changes. ${ }^{32}$ Similarly, Edling and Tagesson found a 20\% prevalence of raised serum bile acid concentrations in sewage pipe fabricators with low exposure to styrene (based on urine mandelic acid values $<1.3 \mathrm{mmol} / \mathrm{l}$ ), compared with a prevalence of $47 \%$ in the high exposure group. ${ }^{33} \mathrm{By}$ contrast, Harkonen et al did not find increases in serum bile acids in polyester plastic fabricators exposed to lower concentrations of styrene. ${ }^{26}$ Although our investigation did not include measurements of serum bile acid, it supports the conclusion that tests of hepatobiliary clearance may serve as useful biomarkers of early subclinical hepatotoxic effects in workers exposed to styrene.

There are several limitations to the two studies comprising this investigation. Firstly, these were cross sectional studies the causal inference of which is inherently limited by potential selection biases. Secondly, although potential confounders were adjusted for, serological tests to exclude subjects with evidence for chronic active hepatitis were only available for study 2 . However, the low proportion of ALT abnormalities (defined clinically as $>50 \mathrm{IU} / \mathrm{ml}$ ) in study 1 , found in only $7.1 \%$ of referents and $6.2 \%$ of exposed subjects, argues against confounding from viral hepatitis in the first study. Thirdly, the standard diazo assay used to characterise bilirubin in these investigations provides only an estimate, not a precise measurement, of conjugated bilirubin. It is unlikely that styrene would enhance the reaction of conjugated bilirubin with the diazo reagent, which requires both an aqueous and acidic medium. ${ }^{20}$ Although some modulation of the 
spectrophotometric measurement of bilirubin by styrene in blood cannot be excluded, the consistent findings of increased serum bile acid concentrations - which were measured by gas chromatography rather than spectrophotometric methods - in other populations exposed to styrene ${ }^{32} 33$ weighs against an artifactual association. Although widely used diazo assays provide a good estimate of conjugated and protein bound bilirubin species in carefully standardised laboratories, ${ }^{34}$ highly specific liquid chromatography yields the most accurate measure of conjugated bilirubin. ${ }^{35}{ }^{36}$ Fourthly, specificity for bilirubin measurement is limited by variation between people in several factors, including haematological conditions associated with overproduction of bilirubin, congenital abnormalities compromising bilirubin clearance, biliary obstruction, and other technical variations in specimen storage and assay methods. $^{293738}$ For these reasons, direct bilirubin concentrations are likely to be of limited clinical value in assessing hepatic function in individual workers, and should appropriately be restricted to population analyses. Fifthly, as well as styrene, workers in fibreglass reinforced plastics are also exposed to acetone. Although acetone is considered to be of low hepatotoxicity, some studies have shown altered styrene metabolism - with diminished production of mandelic and phenylglycoxylic acid-in workers exposed to mixtures of styrene and acetone. ${ }^{39}{ }^{40}$ Although no evidence of microsomal injury has been found in exposure to high doses of styrene and acetone in rats ${ }^{41}$ the possibility that such an interaction might potentiate the hepatotoxic effect of styrene, through accumulation of intermediates such as styrene oxide, cannot be excluded. Finally, it must be emphasised that for all hepatic biochemical variables, our findings represent population trends, and that concentrations were generally within laboratory reference limits for exposed workers. The clinical significance of mild alterations in hepatic clearance on a population basis remains uncertain. Longitudinal studies of hepatic function in populations exposed to styrene will be needed to further characterise the natural history of such changes.

In conclusion, the results of these two independent investigations indicate that exposure to styrene below $50 \mathrm{ppm}$ is associated with mild increases in hepatic transaminase concentrations, with evidence of diminished hepatic clearance of conjugated bilirubin. This alteration in hepatic clearance seems to be associated with mild cholestasis. These findings suggest mild subclinical injury associated with lower exposures to styrene, characterised by diminished clearance of endogenous organic anions such as conjugated bilirubin. On a population basis, our findings point to the use of screening tests assessing hepatic biochemical function in the surveillance of workers exposed to low to moderate concentrations of styrene. For this, fractionated serum bilirubin concentrations may provide a non-invasive, clinically available tool for screening populations of early hepatic effects among workers exposed to styrene.
This research was supported by grants from the National Institute for Occupational Safety and Health (OH-02629), and the National Institute for Environmental Health Sciences (5-K07ES00237-02 Environmental and Occupational Medicine Academic Award), and ES04696.

1 Bond JA. Review of the toxicology of styrene. CRC Reviews in Toxicology 1989;19:227-49.

2 Marniemi J, Suolinna EM, Kaartinen N, et al. Covalent binding of styrene oxide to rat liver macromolecules in vivo and in vitro. In: Ullrich V, ed. Microsomes and drug oxidations. New York: Pergamon, pp. 698-702, 1977.

3 Lof A. Toxicokinetics of styrene biotransformation and covalent binding. Arbete Och Halsa 1986;6:7-87.

4 Anda J, Smith BR, Fouts JR, et al. Concentration-dependent metabolism and toxicity of ${ }^{14} \mathrm{C}$-styrene oxide in the isolated perfused rat liver. F Pharmacol Exp Ther 1979;211:207-11.

5 Srivastava SP, Das M, Mushtaq M, et al. Hepatic effects of orally administered styrene in rats. F Appl Toxicol 1982;2. 219-22.

6 Chakrabarti S, Brodeur J. Metabolism and acute hepatotoxicity of styrene oxide in rats. F Toxicol Environ Health 1981; 8:113-20

7 Sumner SC, Cattley RC, Asgharian B, et al. Evaluation of the metabolism and hepatotoxicity of styrene in F344 rats, $\mathrm{B} 6 \mathrm{C} 3 \mathrm{~F} 1$ mice, and $\mathrm{CD}-1$ mice following single and repeated inhalation exposures. Chem Biol Interact 1997;106: repeated

8 Lundberg I, Ekdahl M, Kronevi T, et al. Environ Res 1986; 40:411-20.

9 Costa AK, Trudell JR. Toxicity of styrene vapor in hepatocyte monolayers at low oxygen tensions. Environ Health Perspect 1990;84:209-13.

10 Axelson O, Gustavson J. Some hygienic and clinical observations on styrene exposure. Scand $\mathcal{f}$ Work Environ Health 1978;4(suppl 2):215-19.

11 Thiess AM, Friedheim M. Morbidity among persons employed in styrene production, polymerization and processing plants. Scand 7 Work Environ Health 1978; 4(suppl 2):203-14.

12 Triebig G, Lehrl S, Weltle D, et al. Clinical and neurobehavioural study of the acute and chronic neurotoxicity of styrene. Br f Ind Med 1989;46:799-804.

13 Lorimer WV, Lilis R, Fischbein A, et al. Health status of styrene-polystyrene polymerization workers. Scand $\mathcal{f}$ Work styrene-polystyrene polymerization worke
Environ Health 1978;4(suppl 2):220-6.

14 Lenvik K, Osvoll PO, Woldbaek T. Occupational exposure to styrene in Norway. Appl Occup Environ Hyg 1999;14: $165-70$

15 National Institute for Occupational Safety and Health. Manual of laboratory methods. Washington, DC: Government Printing Office, 1985.

16 Dills RL, Wu RL, Checkoway H, et al. Quantitation of volatile solvents in blood using static headspace analysis. Talanta 1991;38:365-74.

17 Stolz A, Kaplowitz N. Biochemical tests for liver disease. In: Zakim D, Boyer TD, eds. Hepatology. Philadelphia: WB Saunders, 1990:637-57.

18 Seetharam S, Sussman NL, Komoda $\mathrm{T}$, et al. The mechanism of elevated alkaline phosphatase activity after bile duct ligation in the rat. Hepatology 1986;6:374.

19 Whitfield JB, Pounder RE, Neale G, et al. Serum $\gamma$-glutamyl transpeptidase activity in liver disease. Gut 1972;13:702.

20 Blanckaert N, Heirwegh KPH. Analysis and preparation of bilirubins and biliverdins. In: Ostrow JD, ed. Bile pigments bilirubins and biliverdins. In: Ostrow JD, ed. Bile pign
and jaundice. New York: Marcel Dekker, 1986:31-79.

21 Clarenberg R, Kao CC. Shared and separate pathways for biliary excretion of bilirubin and BSP in rats. Am $\mathcal{F}$ Physiol 1973;225:192

2 Nosslin B. The direct diazo reaction of bile pigments in serum. Scand F Clin Lab Invest 1960;12(suppl 49):5.

23 Tisdale WA, Klatskin G, Kinsella ED. The significance of the direct-reacting fraction of serum bilirubin in hemolytic jaundice. Am F Med 1959;26:214.

24 Scharschmidt BF. Bile formation and cholestasis. In: Zakim D, Boyer TD, eds. Hepatology. Philadelphia: WB Saunders, 1990:303-40.

25 Lorimer WV, Lilis R, Nicholson WJ, et al. Clinical studies of styrene workers: initial findings. Environ Health Perspect 1976;17:171-81.

26 Harkonen H, Lehtniemi A, Aitio A. Styrene exposure and the liver. Scand $\mathcal{F}$ Work Environ Health 1984;10:59-61.

27 Cohen JA, Kaplan MM. The SGOT/SGPT ratio as an indiCohen JA, Kaplan MM. The SGOT/SGPT ratio as an indi-
cator of alcoholic liver disease. Dig Dis Sci 1979;24:835-8. cator of alcoholic liver disease. Dig Dis Sci 1979;24:835-8.
28 Fleming LE, Shalat SL, Redlich CA. Liver injury in workers exposed to dimethylformamide. Scand $\mathcal{F}$ Work Environ Health 1990;16:289-92.

29 Blanckaert N, Fevery J. Physiology and pathophysiology of bilirubin metabolism. In: Zakim D, Boyer TD, eds. Hepatology. Philadelphia: WB Saunders, 254-302.

30 Katz B. Toxicochemical affection of the liver with styrene under operating conditions. Gigiena Truda 1962;10:21-3.

31 Oltramare M, Desbaumes E, Imhoff C, et al. Toxicologie du Styrene Monomere. Geneva: Editions Medicine et Hygiene 1974:1-91.

32 Vihko R, Vihko P, Maentausta O, et al. Assessment of early hepatotoxicity. In: Aitio A, Riihimaki V, Vainio H, ed. Biological monitoring and surveillance of workers exposed to Biological monitoring and surveillance of workers exposed to
chemicals. Washington, DC: Hemisphere, 1984:309-13.

33 Edling C, Tagesson C. Raised serum bile acid concentrations after occupational exposure to styrene: a possible sign tions after occupational exposure to styrene: a po
of hepatotoxicity? $\mathrm{Br}$ f Ind Med 1984;41:257-9.

34 Westwood A. The analysis of bilirubin in serum. Ann Clin Biochem 1991;28:119-30. 
35 Blanckaert N, Kabra PM, Farina FA, et al. Measurement of bilirubin and its monoconjugates and diconjugates in human serum by alkaline methanolysis and highperformance liquid chromatography. F Lab Clin Med 1980 96:198.

36 Blanckaert N. Analysis of bilirubin and bilirubin mono- and diconjugates. Determination of their relative amounts in biological fluids. Biochem $\mathcal{F}$ 1980;185:115.

37 Lolekha PH, Limpavithayakul K. Unreliable estimation of direct bilirubin in serum by two continuous flow methods. Clin Chem 1977;23:2133.

38 Killenberg PG, Stevens RD, Wildermann RF, et al. The laboratory method as a variable in the interpretation of serum bilirubin fractionation. Gastroenterology 1980;78: 1011.

39 Marhuenda D, Prieto M, Periago JF, et al. Biological monitoring of styrene exposure and possible interference of acetone co-exposure. Int Arch Occup Environ Health 1997;69:455-60.

40 Apostoli P, Alessandro G, Placidi D, et al. Metabolic interferences in subjects occupationally exposed to binary styrene-acetone mixtures. Int Arch Occup Environ Heath 1998;71:445-52.

41 Vainio H, Zitting A. Interaction of styrene and acetone with drug biotransformation enzymes in rat liver. Scand $\mathcal{f}$ Work Environ Health 1978;4(suppl 2):47-52.

\section{Open reviewing}

Many journals, including the BMJ, have moved to a system of open reviewing, whereby authors know the names of reviewers of their papers. Research has shown that named reviews, although not of better quality than anonymous reviews, are not of worse quality either. Therefore in the interests of transparency, it seems fair to let authors know who has reviewed their paper. At Occupational and Environmental Medicine we have considered the issue carefully. There are some concerns that reviewers, especially those who are more junior, might feel intimidated and not wish to make negative comments about papers submitted by senior people in the field. On the other hand, some reviewers might hide behind the cloak of anonymity to make unfair criticisms so as to reduce the chances of publication by rivals. We have decided to introduce initially a system of open reviewing if the reviewers agree explicitly. So when a reviewer is sent a paper, he or she is asked to indicate whether we can disclose their name or not when sending the authors their comments. We will be monitoring this to see how many of our reviewers are happy to be named. If it is most of them, we will move to a system of open reviewing as the norm, with a possible "opt out" clause for reviewers. 